\title{
MicroRNA-383 promotes reactive oxygen species-induced autophagy via downregulating peroxiredoxin 3 in human glioma U87 cells
}

\author{
ZHOU XU $^{1}$, XINGRUO ZENG $^{2}$, MINGCHANG LI $^{1}$, JIANMING LIAO $^{1}$ and QIANXUE CHEN ${ }^{1}$ \\ ${ }^{1}$ Department of Neurosurgery, Renmin Hospital of Wuhan University, Wuhan, Hubei 430060; \\ ${ }^{2}$ Department of Nephrology and Rheumatology, The Central Hospital of Wuhan, \\ Huazhong University of Science and Technology, Wuhan, Hubei 430014, P.R. China
}

Received July 31, 2019; Accepted June 10, 2020

DOI: $10.3892 /$ etm.2021.9870

\begin{abstract}
Peroxiredoxin 3 (PRDX3) is an abundant and effective enzyme, which aids in the removal of $\mathrm{H}_{2} \mathrm{O}_{2}$ in the mitochondria, thereby inhibiting cell autophagy. PRDX3 is a target protein of microRNA (miRNA/miR)-383, the overexpression of which has been found to inhibit the growth of glioma cells. We hypothesized that miR-383 serves an antitumor role by inhibiting oxidative stress during tumor growth. In the current study, human glioma U87 cells were transfected with pre-/short hairpin (sh)-PRDX3 vectors and miR-383 mimics/inhibitors. Apoptosis and reactive oxygen species (ROS) production were detected using flow cytometry. Autophagy was examined using acridine orange staining, and the expression of cytoplasmic autophagy-related proteins [autophagy-related protein 9 (ATG9), Ras-related protein Rab-1A (Rab1) and p62] was determined using western blot analysis. The interaction between miR-383 and PRDX3 was assessed using a dual-luciferase assay. The results indicated that both sh-PRDX3 and miR-383 mimics promoted apoptosis and increased the level of mitochondrial ROS, whilst acridine orange staining revealed that sh-PRDX3 promoted autophagy in U87 cells compared with that in the control cells. The detection of autophagic proteins indicated that sh-PRDX3 and $\mathrm{miR}-383$ mimics increased the protein expression level of ATG9 and RAB1, and inhibited that of p62. On the contrary, the effect of miR-383 mimics was opposite to that of pre-PRDX3 in
\end{abstract}

Correspondence to: Dr Qianxue Chen, Department of Neurosurgery, Renmin Hospital of Wuhan University, 238 Jiefang Road, Wuchang, Wuhan, Hubei 430060, P.R. China

E-mail: chenqx666@126.com

Abbreviations: PRDX3, peroxiredoxin 3; RT-qPCR, reverse transcription-quantitative PCR; DCFH-DA, 2',7'-dichlorodihydro fluorescein diacetate

Key words: autophagy, glioma, reactive oxygen species, microRNA-383, PRDX3
U87 cells. Reverse transcription-quantitative PCR and western blot assays revealed that miR-383 was negatively associated with PRDX3 in U87 cells. miR-383 was indicated to interact with PRDX3, as demonstrated using a dual-luciferase assay. In conclusion, the present study demonstrated that miR-383 induced cell apoptosis and mitochondrial ROS production by downregulating PRDX3 in U87 cells, thereby promoting oxidative stress-induced autophagy.

\section{Introduction}

Glioma has been indicated to be the most common primary brain tumor, accounting for $75 \%$ of all intracranial tumors in adults from 2010-2014 in USA (1), with a diagnosis of $\sim 350,000$ cases per year. There has been substantial progress in the treatment of glioma; however, the median survival time of patients with glioblastoma has been reported to be only 12-15 months worldwide in 2013 (2). Therefore, the discovery of novel molecular targets and therapeutic methods for the treatment of glioma are required.

MicroRNAs (miRNAs/miRs) are small non-coding RNAs that have been discovered $\sim 20$ years ago $(3,4)$. miRNAs have been associated with a number of important biological processes, including developmental regulation, organ formation, cell proliferation and apoptosis $(5,6)$. Previous studies have indicated that several miRNAs were abnormally expressed and participated in the occurrence and development of glioma $(7,8)$. miR-383 has been indicated to be downregulated in hepatocellular carcinoma and non-small cell lung cancer, acting either as a tumor suppressor gene $(9,10)$. Moreover, a previous study has reported that the inhibition of miR-383 in glioma tissue decreased the proliferation of glioma cells (11). However, the mechanism by which miR-383 may affect the proliferation or apoptosis of glioma cells is still unclear.

Peroxiredoxin 3 (PRDX3) is an oxidation/reductionrelated protein found in the mitochondria, which has been found to exhibit protective antioxidant effects and inhibit autophagy $(12,13)$. PRDX3 has been reported to promote cancer cell survival by aiding cancer cells to escape cell oxidation, and the protein expression levels of PRDX3 has been negatively associated with autophagy $(12,14)$. Previously, 
PRDX3 has been identified as a target protein of miR-383, and a negative association between the expression levels of miR-383 and PRDX3 was found (15). Therefore, based on these studies, miR-383 may exert antitumor effects via the oxidative stress pathway to inhibit tumor growth. Mitochondrial reactive oxygen species (ROS) are considered to be harmful products of oxidative metabolism, as they cause cell damage and result in diseases, including diabetes and cardiovascular diseases (16-19). Previous studies have reported that oxidative stress may disrupt endoplasmic reticulum function (20), activate endoplasmic reticulum stress $(21,22)$ and downregulate autophagy $(23,24)$. Whether an association between miR-383 and autophagy via PRDX3-mediated oxidative stress exists, remains to be further elucidated.

The present study examined the effects of manipulating the expression levels of miR-383 and PRDX3 on apoptosis, mitochondrial ROS production and autophagy in human glioma U87 cells. In addition, the present study also explored whether PRDX3 is a downstream target gene of miR-383, with the aim to clarify the potential mechanism by which miR-383 may regulate autophagy in human glioma cells.

\section{Materials and methods}

Cell culture. The U87 cell line (accession no. CVCL_0022; American Type Culture Collection), which is a glioblastoma cell line of unknown origin, that was authenticated using STR profiling, was maintained in DMEM (Invitrogen; Thermo Fisher Scientific, Inc.) supplemented with 10\% FBS (Gibco; Thermo Fisher Scientific, Inc.), $50 \mathrm{U} / \mathrm{ml}$ penicillin and $50 \mathrm{mg} / \mathrm{ml}$ streptomycin. The cells were cultured in an atmosphere at $37^{\circ} \mathrm{C}$ containing $5 \% \mathrm{CO}_{2}$.

Construction of miR-383 mimics/inhibitors and PRDX3 interferenceloverexpression vectors. The commercial miR-383 mimics/inhibitors and their negative controls $(\mathrm{NCs})$ were purchased from Guangzhou RiboBio Co., Ltd. (miR-383 mimics, cat. no. miR10000748-1-5; miR-383 inhibitors, cat. no. miR20000748-1-5; mimics NC, cat. no. miR1N0000001-1-5; inhibitors NC, cat. no. miR2N0000001-1-5). The sequences are as follows: miR-383 mimic, 5'-AGAUCAGAAGGUGAUUGU GGCU-3' and miR-383 inhibitor, 5'-AGCCACAAUCACCUU CUGAUCU-3'.

The small interfering RNA Target Finder(https://rnaidesigner. thermofisher.com/rnaiexpress/design.do;Ambion;ThermoFisher Scientific, Inc.) was used to select a segment (5'-AACGAGCTT GACAATCTCTTGAA-3') within the coding region of PRDX3 (NC_000010.11) for the short hairpin (sh)RNA design. The corresponding DNA template sequence containing restriction sites for $E c o$ RI and BamHI was used, as a target sequence. The template primer sequences were as follows: Sense, 5'-GATCCGGAA GAACGAGCTTGACAATTCAAGAGATTGTCAAGCTCGTTC TTCCTTTTTTACGCGTG-3'; antisense, 5'-AATTCACGC GTAAAAAAGGAAGAACGAGCTTGACAATCTCTTGAA TTGTCAAGCTCGTTCTTCCG-3'. The shRNA sequence, which was obtained using PCR, and pSIREN-RetroQ-shN plasmid vector, which was a gift from Joe Landry (Addgene plasmid no. 73665; http://n2t.net/addgene:73665; RRID:Addgene_73665), was digested using EcoRI and BamHI enzymes (Thermo Fisher Scientific, Inc.) and subsequently ligated. The recombinant plasmid (pSIREN-sh-PRDX3) was transfected into U87 cells using Lipofectamine ${ }^{\circledR} 2000$ (Invitrogen; Thermo Fisher Scientific, Inc.).

The pre-PRDX3 plasmid was constructed using the same method as aforementioned. The corresponding DNA template containing restriction sites for EcoRI and XhoI was designed as a target sequence. The template primer sequences were as follows: Forward primer, 5'-CGGAATTCCGATGGCGGC TGCTGTA-3'; reverse primer, 5'-CCCTCGAGGGTTACC TTCTGAAAGTA-3'. pcDNA3.1-HA plasmid, which was a gift from Oskar Laur (Addgene plasmid no. 128034; http://n2t. net/addgene:128034; RRID:Addgene_128034), was digested using EcoRI and XhoI enzymes (Thermo Fisher Scientific, Inc.) and ligated to the PRDX3 sequence obtained using PCR from DNA template from U-87 MG cells according to the following system: $12.5 \mu \mathrm{l}$ PCR mix (2xTaq Master Mix; Vazyme Biotech Co., Ltd.), $0.5 \mu \mathrm{l}$ forward primer, $0.5 \mu \mathrm{l}$ reverse primer, $1 \mu \mathrm{l}$ DNA template and $10.5 \mu \mathrm{ldd} \mathrm{d}_{2} \mathrm{O}$. The thermocycling conditions are as follows: Initial denaturation at $94^{\circ} \mathrm{C}$ for $3 \mathrm{~min}$, followed by 30 cycles of denaturation at $94^{\circ} \mathrm{C}$ for $60 \mathrm{sec}$, annealing at $56^{\circ} \mathrm{C}$ for $60 \mathrm{sec}$, and extension at $72^{\circ} \mathrm{C}$ for $60 \mathrm{sec}$; and final extension at $72^{\circ} \mathrm{C}$ for $5 \mathrm{~min}$. The recombinant plasmid (pcDNA3.1-prePRDX3) was transfected into U87 cells using Lipofectamine ${ }^{\circledR}$ 2000 (Invitrogen; Thermo Fisher Scientific, Inc.).

Cell transfection. U87 cells $\left(1 \times 10^{5}\right.$ cells/well) were seeded in 6-well plates at $37^{\circ} \mathrm{C}$ overnight and transfected with miR-383 mimics/inhibitors $(20 \mathrm{nM})$ and miR-383 mimics/inhibitors NCs, pre-/sh-PRDX3 (0.8-1.0 $\mu \mathrm{g}$ ), scramble shRNA (sh-NC) or pre-NC using Lipofectamine ${ }^{\circledR} 2000$ (Invitrogen; Thermo Fisher Scientific,Inc.). During transfection, the cells were maintained in Opti-MEM reduced-serum medium (Gibco; Thermo Fisher Scientific, Inc.) for $6 \mathrm{~h}$ at $37^{\circ} \mathrm{C}$, and subsequently the medium was replaced with DMEM. The cells were analyzed using reverse transcription-quantitative PCR (RT-qPCR) and western blot analysis following $48 \mathrm{~h}$ of transfection.

Flow cytometry. To detect ROS levels, 2',7'-dichlorodihydrofluorescein diacetate (DCFH-DA; Sigma-Aldrich; Merck $\mathrm{KGaA})$ was diluted with serum-free DMEM $(1: 1,000$; HyClone; Cytiva) to a final concentration of $10 \mu \mathrm{mol} / 1$. U87 cells were collected by centrifugation at $400 \mathrm{xg}, 4^{\circ} \mathrm{C}$ for $5 \mathrm{~min}$, suspended in diluted DCFH-DA $(10 \mu \mathrm{mol} / \mathrm{l})$ at $1 \times 10^{7} \mathrm{cells} / \mathrm{ml}$ and incubated at $37^{\circ} \mathrm{C}$ for $20 \mathrm{~min}$. The cell suspension was mixed every 3-5 min to fully integrate the probe with the cells. Following incubation, the cells were washed three times with serum-free medium to remove excessive DCFH-DA. The cells $\left(1 \times 10^{6}\right)$ were subsequently harvested by centrifugation at $400 \times \mathrm{g}, 4^{\circ} \mathrm{C}$ for $5 \mathrm{~min}$, and ROS levels were detected using flow cytometry (FC500 MCL; Beckman Coulter, Inc.). The data was analyzed using CXP analysis version 2.0 (Beckman Coulter, Inc.).

To detect apoptosis, U87 cells $\left(1 \times 10^{6}\right)$ were collected and washed with $1 \mathrm{ml}$ pre-cooled PBS. Annexin V-FITC and propidium iodide (10 $\mu 1$ each; both Beijing Solarbio Science and Technology Co., Ltd.) were added to the cells and the percentage of apoptosis in the stained cells was quantified using flow cytometry (FC500 MCL; Beckman Coulter, Inc.). The data was analyzed using CXP Analysis version 2.0 (Beckman Coulter, Inc.). 
Western blot analysis. U87 cells were lysed in pre-cooled RIPA lysis buffer (Beyotime Institute of Biotechnology). Protein quantification was performed using bicinchoninic acid protein concentration determination assay (Thermo Fisher Scientific, Inc.). Following incubation in a water bath for $10 \mathrm{~min}, 25 \mu \mathrm{g}$ protein/lane were subjected to SDS-PAGE on $12 \%$ gels. The proteins were transferred to a PVDF membrane (EMD Millipore), blocked in $5 \%$ skim milk at $25^{\circ} \mathrm{C}$ for $2 \mathrm{~h}$ and incubated with primary antibodies (all 1:1,000) against PRDX3 (cat. no. ab73349; Abcam), autophagy-related protein 9 (ATG9; cat. no. ab108338; Abcam), Ras-related protein Rab-1 (RAB1; cat. no. 13075; Cell Signaling Technology, Inc.), p62 (cat. no. ab91526; Abcam) and GAPDH (cat. no. 5174; Cell Signaling Technology, Inc.) overnight at $4^{\circ} \mathrm{C}$. The membranes were subsequently washed 3 times with PBS containing $5 \%$ Tween-20 and incubated with goat anti-rabbit IgG horseradish peroxidase-conjugated secondary antibody $(1: 2,000$; cat. no. ab6721; Abcam) at $25^{\circ} \mathrm{C}$ for $1 \mathrm{~h}$. The membranes were treated with ECL reagent (EMD Millipore) to detect the expression of proteins using an automatic chemiluminescence analyzer (Tanon 5200; Tanon Science and Technology Co., Ltd.). The band gray values were read using the Tanon GIS 4.2 software (Tanon Science and Technology Co., Ltd.).

$R T-q P C R$. Total RNA was extracted from U87 cells using TRIzol $^{\circledR}$ reagent (Invitrogen; Thermo Fisher Scientific, Inc.) and reverse-transcribed into cDNA using the Advantage ${ }^{\circledR}$ RT-for-PCR Kit (cat. no. 639505; Takara Biotechnology Co., Ltd.). The reverse transcription condition were as follows: $42^{\circ} \mathrm{C}$ for 15 min and hold at $16^{\circ} \mathrm{C}$. SYBR ${ }^{\circledast}$ Premix Ex Taq ${ }^{\mathrm{TM}}$ II kit (Takara Biotechnology Co., Ltd.) was used for subsequent qPCR according to the manufacturer's instructions. The thermocycling conditions were as follows: Initial denaturation at $95^{\circ} \mathrm{C}$ for $3 \mathrm{~min}$, followed by 39 cycles of denaturation at $95^{\circ} \mathrm{C}$ for $5 \mathrm{sec}$, annealing at $56^{\circ} \mathrm{C}$ for $10 \mathrm{sec}$ and extension at $72^{\circ} \mathrm{C}$ for $25 \mathrm{sec}$, before final extension at $65^{\circ} \mathrm{C}$ for $5 \mathrm{sec}$ and $95^{\circ} \mathrm{C}$ for $50 \mathrm{sec}$. All primers were purchased from Nanjing Genscript Biological Technology Co., Ltd., and were as follows: PRDX3 forward, 5'-TTCCAGTCAAGCAAAAT-3' and reverse, 5'-GAAGAAAAGCACCAAAT-3'; miR-383 forward, 5'-GGG AGATCAGAAGGTGA-3' and reverse, 5'-AACTGGTGTCGT GGAGTCGGC-3'; U6 forward, 5'-CTCGCTTCGGCAGCA CA-3' and reverse, 5'-AACGCTTCACGAATTTGCGT-3' and GAPDH forward, 5'-CCACTCCTCCACCTTTG-3' and reverse, 5'-CACCACCCTGTTGCTGT-3'. The experiments were performed independently with three biological replicates. The data was analyzed using the $2^{-\Delta \Delta C q}$ method (25), where GAPDH was used as the reference gene of PRDX3 and U6 was used as the reference gene of miR-383.

Acridine orange staining. An Acridine Orange detection kit (Beijing Leagene Biotech Co., Ltd.) was used to detect cell autophagy. A total of $1 \times 10^{6} \mathrm{U} 87$ cells/ml were washed with acridine orange (AO) stain buffer (1X) and subsequently mixed with AO stain buffer (1X) at a ratio of 19:1 (v/v). The cells were stained at $25^{\circ} \mathrm{C}$ for $15 \mathrm{~min}$, placed on a glass slide and covered with a coverslip. Subsequently, images were obtained (magnification, x200) using a fluorescence microscope (excitation filter wavelength, $488 \mathrm{~nm}$; blocking filter wavelength, $515 \mathrm{~nm}$; IX53; Olympus Corporation).
Interaction between miR-383 and PRDX3. The 3'-untranslated region (3'-UTR) of the PRDX3 gene and potential targets of miR-383 were predicted using the TargetScanHuman v7.1 software (http://www.targetscan.org/vert_71/). The QuikChange Site-Directed Mutagenesis kit (Agilent Technologies, Inc.) was used to mutate the $3^{\prime}-\mathrm{UTR}$ of PRDX3 at the putative binding site of miR-383. Wild-type (WT) and mutant (Mut) PRDX3 3'-UTRs were cloned into the pmirGLO-vector (Promega Corporation). 293 cells were co-transfected with pmirGlO-3'UTR-PRDX3 (50 ng) and miR-383 mimics/inhibitor (50 $\mathrm{nM}$ ) using Lipofectamine ${ }^{\circledR} 2000$ (Invitrogen; Thermo Fisher Scientific, Inc.) in 24-well plates for $12 \mathrm{~h}$. Following transfection, cell lysates were prepared using Passive Lysis Buffer (Promega Corporation) and luciferase activity was measured using a Dual-Luciferase ${ }^{\circledast}$ Reporter assay system according to manufacturer's protocol (Promega Corporation). All luciferase activities were normalized to that of Renilla luciferase activity.

Statistical analysis. SPSS v19.0 (IBM Corp.) was used to analyze all data, and the data are presented as the mean \pm standard deviation from three experimental repeats. Statistical analysis was performed using one-way ANOVA followed by Dunnett's or Duncan's test. $\mathrm{P}<0.05$ was considered to indicate a statistically significant difference.

\section{Results}

Efficiency ofpre-/sh-PRDX3 vectors and miR-383 mimics/inhibitor and their effect on the expression of autophagy-associated proteins. The mRNA and protein expression level of PRDX3 was increased in the pre-PRDX3 group and decreased in sh-PRDX3-transfected cells compared with that in the control cells $(\mathrm{P}<0.05)$, indicating that the transfection of pre-/sh-PRDX3 plasmids was successful (Fig. 1A and C). In addition, the mRNA expression level of miR-383 was increased following transfection with miR-383 mimics and decreased in cells transfected with miR-383 inhibitor compared with that in the control cells $(\mathrm{P}<0.05)$, demonstrating that transfection with miR-383 mimics and inhibitor was also successful (Fig. 1B). Additionally, neither miR-383 mimics/inhibitors negative controls or pre-/sh-PRDX3 negative controls exerted an effect on miR-383 or PRDX3 expression (Fig. S1). Therefore, the NC groups were not take into consideration in the follow-up study. Moreover, the autophagyrelated proteins, ATG9, RAB1 and p62, were examined using western blot analysis following pre-/sh-PRDX3 transfection. ATG9 and RAB1 were downregulated in cells transfected with pre-PRDX3 $(\mathrm{P}<0.05$ and $\mathrm{P}<0.01$, respectively), but were upregulated in cells transfected with sh-PRDX3 $(\mathrm{P}<0.05$ and $\mathrm{P}<0.01$, respectively) compared with that in the control cells (Fig. 1C). By contrast, p62 was upregulated by pre-PRDX3 $(\mathrm{P}<0.01)$ and downregulated by sh-PRDX3 $(\mathrm{P}<0.05)$ compared with that in the control group (Fig. 1C).

PRDX3 and miR-383 are associated with ROS and autophagy in human glioma U87 cells. Apoptosis and ROS levels were detected using flow cytometry, following transfection. Compared with that in the control group, cells transfected with pre-PRDX3 exhibited no difference in the rate of apoptosis, whereas sh-PRDX3 significantly increased apoptosis in transfected cells (Fig. 2A; P<0.05). In addition, the miR-383 
A

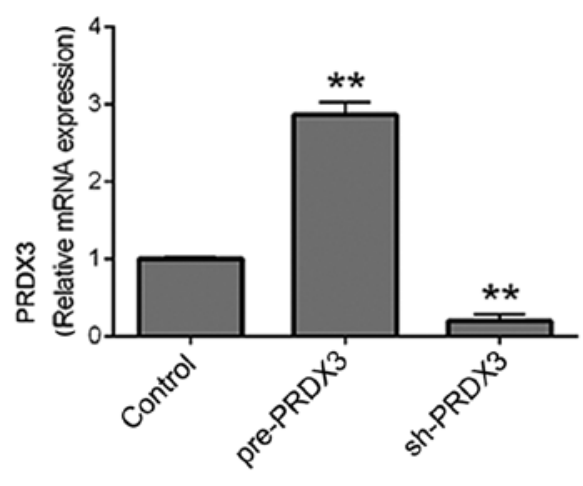

B

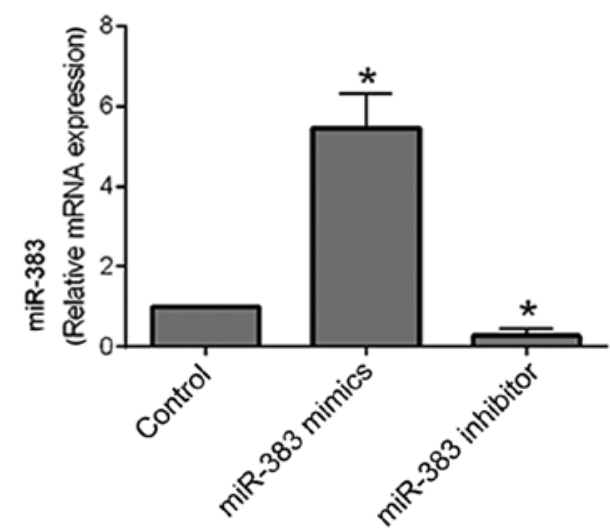

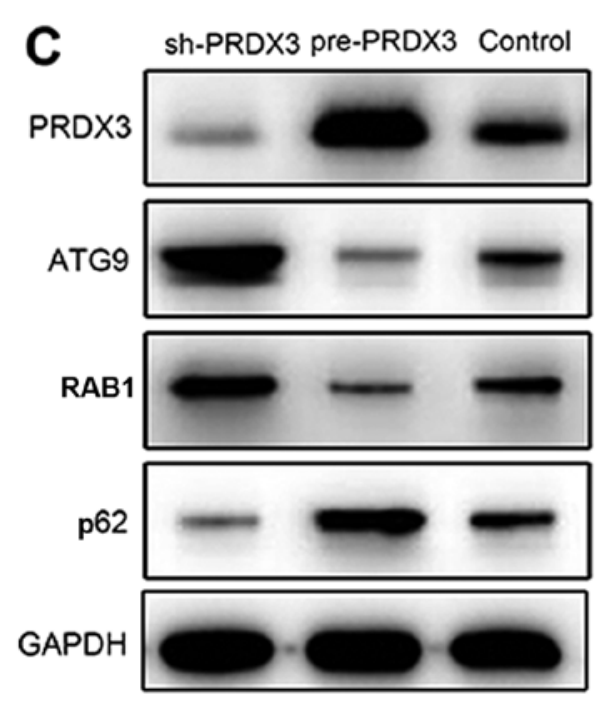
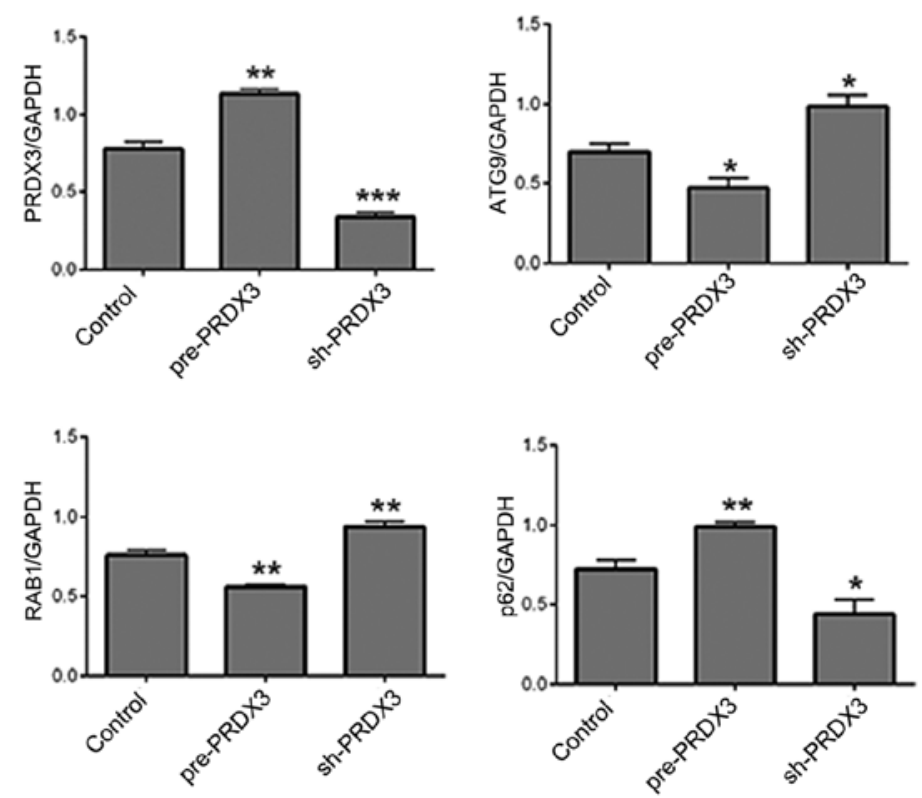

Figure 1. Expression of proteins associated with autophagy after transfection with pre-/sh-PRDX3 vectors and miR-383 mimics/inhibitor. (A) mRNA expression level of PRDX3 in cells transfected with pre-PRDX3, sh-PRDX3 and the control group. (B) mRNA expression level of miR-383 in cells transfected with miR-383 mimics, miR-383 inhibitor and the control group. (C) Protein expression of PRDX3 and the autophagy-related proteins ATG9, RAB1 and p62 in cells transfected with pre-PRDX3, sh-PRDX3 and the control group. $n=3 .{ }^{*} \mathrm{P}<0.05,{ }^{* *} \mathrm{P}<0.01$ and ${ }^{* * *} \mathrm{P}<0.001$ vs. Control group. PRDX3, peroxiredoxin 3; miR, microRNA; sh, short hairpin; ATG9, autophagy-related protein 9; RAB1, Ras-related protein Rab-1.

inhibitor did not affect apoptosis, whereas transfection with miR-383 mimics significantly increased apoptosis compared with that in the control cells (Fig. 2B; $\mathrm{P}<0.05$ ). ROS levels were decreased following transfection with pre-PRDX3 $(\mathrm{P}<0.01)$, but were increased in the sh-PRDX3-transfected cells $(\mathrm{P}<0.05)$ compared with that in the control group (Fig. 2C). Moreover, transfection with miR-383 mimics significantly increased ROS levels $(\mathrm{P}<0.05)$, whereas cells transfected with miR-383 inhibitor exhibited no significant difference compared with that in the control cells (Fig. 2D). Autophagy was examined in U87 cells using AO staining (Fig. 3). Cells transfected with sh-PRDX3 presented an increased autophagy compared with that in the control group and pre-PRDX3-transfected cells, as indicated by the increase in autolysosome formation (Fig. 3A; orange red staining). Similarly, autophagy was enhanced in cells transfected with miR-383 mimics compared with that in the control group and miR-383 inhibitor-transfected cells (Fig. 3B). In addition, the AO staining can also be used to evaluate the apoptosis of cells, which shows yellow-green staining. The increased yellow-green staining in sh-PRDX3 and miR-383 mimics groups suggested increased levels of apoptosis, consistent with results that both sh-PRDX3 and miR-383 mimics promoted apoptosis.

Interaction between miR-383 and PRDX3. RT-qPCR was used to detect the mRNA expression levels of PRDX3 and miR-383 following transfection with miR-383 mimics and inhibitors and pre/sh-PRDX3. The mRNA expression levels of PRDX3 were significantly decreased following transfection with miR-383 mimics $(\mathrm{P}<0.05)$ and significantly increased with miR-383 inhibitor $(\mathrm{P}<0.05)$ compared with that in the control cells (Fig. 4A). In addition, the expression level of miR-383 was significantly downregulated in cells transfected with prePRDX3 $(\mathrm{P}<0.05)$, but was significantly upregulated following transfection with sh-PRDX3 $(\mathrm{P}<0.05)$ compared with that in the control group (Fig. 4B). The protein expression level of PRDX3 was similar to the mRNA levels in cells transfected with miR-383 mimics and inhibitor compared with that in the control cells (Fig. 4C; both $\mathrm{P}<0.05$ ). Moreover, ATG9 and RAB1 were significantly downregulated in cells transfected 

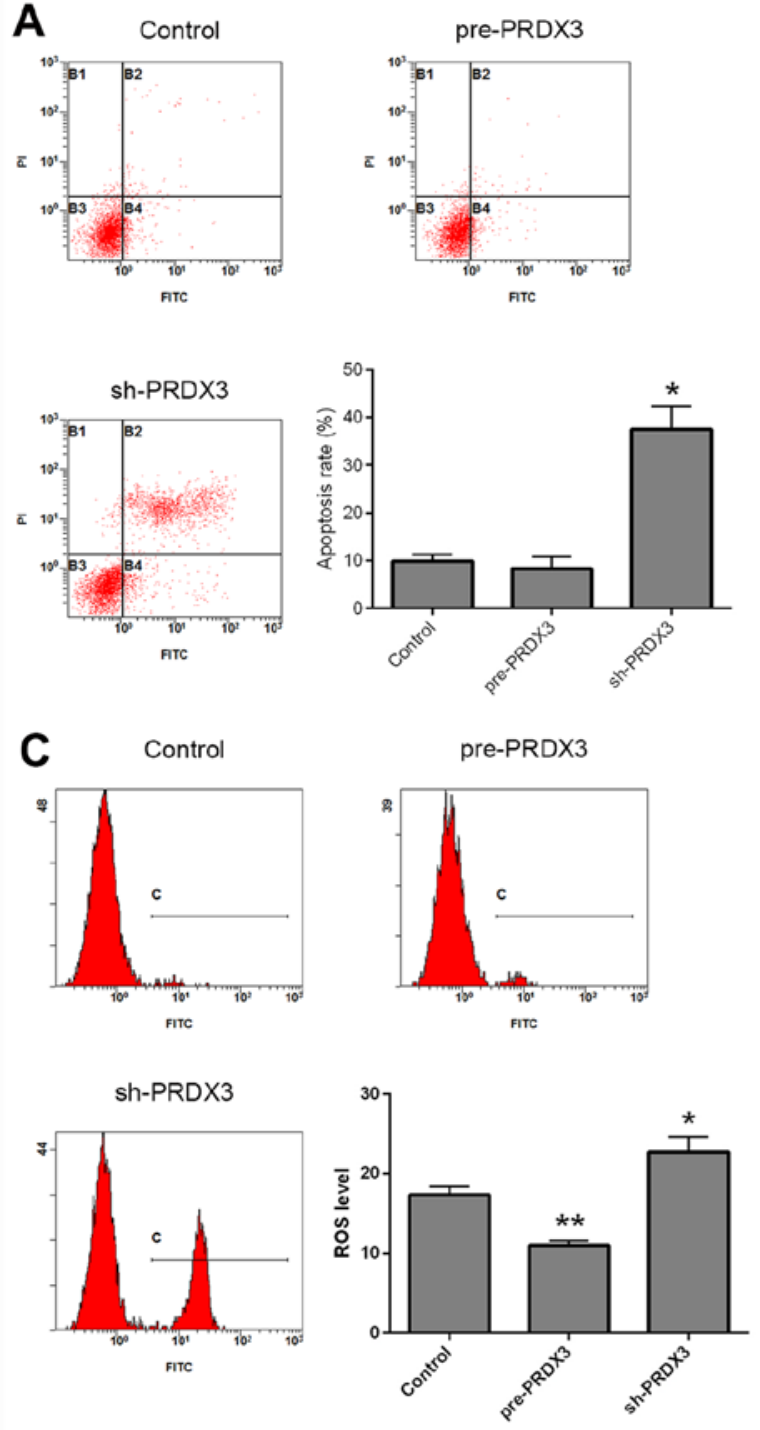
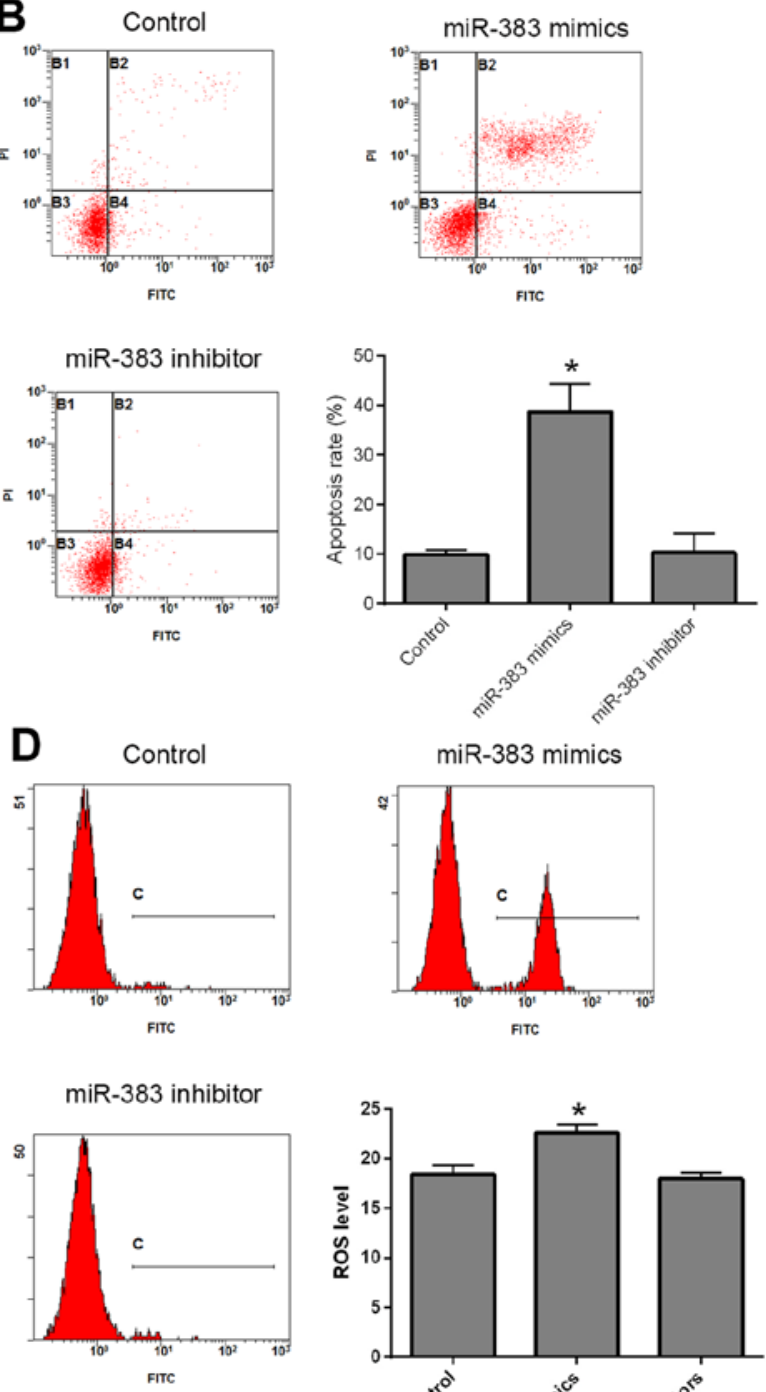

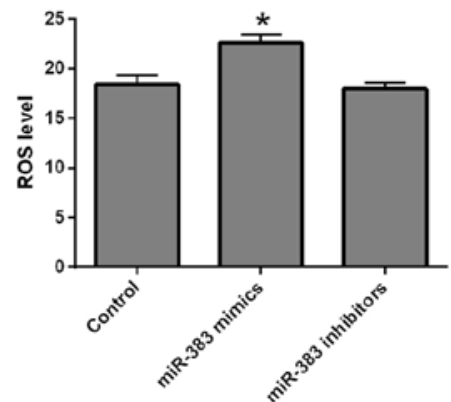

Figure 2. PRDX3 inhibits and miR-383 promotes ROS production in human glioma U87 cells. Flow cytometry detection of cell apoptosis following transfection with (A) pre-/sh-PRDX3 and (B) miR-383 mimics/inhibitor. Flow cytometry detection of ROS levels following transfection with (C) pre-/sh-PRDX3 and (D) miR-383 mimics/inhibitor. $\mathrm{n}=3 .{ }^{*} \mathrm{P}<0.05$ and ${ }^{* *} \mathrm{P}<0.01$ vs. Control group. PRDX3, peroxiredoxin 3 ; miR, microRNA; sh, short hairpin; ROS, reactive oxygen species.

with miR-383 inhibitor (both $\mathrm{P}<0.01$ ), but were significantly upregulated following transfection with miR-383 mimics (both $\mathrm{P}<0.05$ ) compared with that in the control group (Fig. 4C). p62 was also significantly upregulated following transfection with miR-383 inhibitor $(\mathrm{P}<0.05)$, but was significantly downregulated in miR-383 mimics-transfected cells $(\mathrm{P}<0.01)$, compared with that in the control cells (Fig. 4C). The effect of miR-383 on the expression level of autophagy-associated proteins was opposite to that of PRDX3 (Fig. 1C). The potential interaction between miR-383 and PRDX3 was investigated in U87 cells using a dual-luciferase assay (Fig. 4D). In the PRDX3 WT group, luciferase activity was significantly increased following transfection with miR-383 mimics $(\mathrm{P}<0.001)$ and significantly decreased with miR-383 inhibitor $(\mathrm{P}<0.001)$ compared with that in the control group. Moreover, in cells transfected with miR-383 mimics, the luciferase activity of the PRDX3 WT group was significantly increased compared with that in the PRDX3 Mut group $(\mathrm{P}<0.001)$, and in cells transfected with
miR-383 inhibitor, the luciferase activity of the PRDX WT group was significantly decreased compared with that in the PRDX3 Mut group $(\mathrm{P}<0.001)$.

\section{Discussion}

Basu et al (26) previously reported that the expression level of PRDX3 in cells of patients with prostate cancer was higher compared with that in normal prostate cells, and suggested that PRDX3 served a cancer-promoting role. In addition, elevated expression levels of PRDX3 in the serum may be considered to be a marker of prostate carcinogenesis (26). In addition, PRDX3 was found to be overexpressed in glioblastoma and PRDX3 inhibition attenuated glioma cell growth (9). These indicated the tumorigenic role of PRDX3. The majority of PRDX3 is localized in the mitochondria (27); however, PRDX3 expression on the cell membrane has been shown to be regulated by androgens in LNCaP cells, which is a prostate 
A
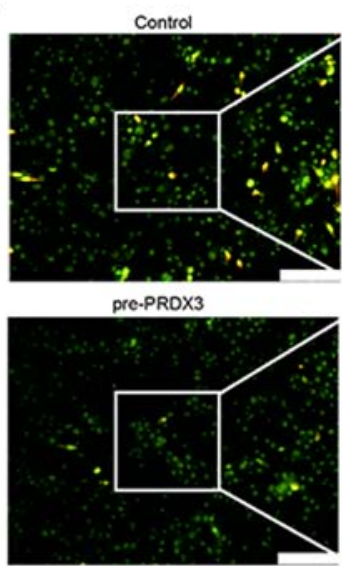

sh-PROX 3

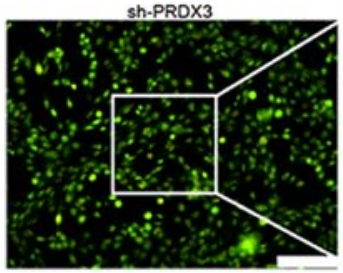

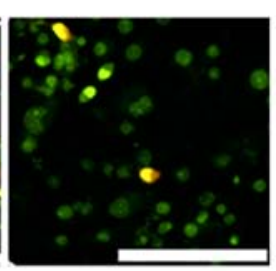
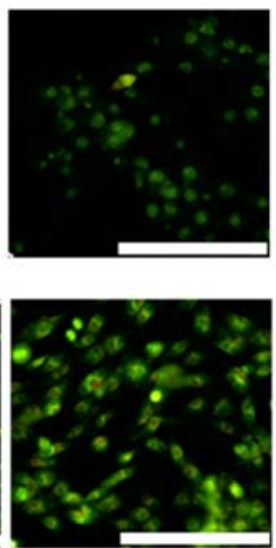

B
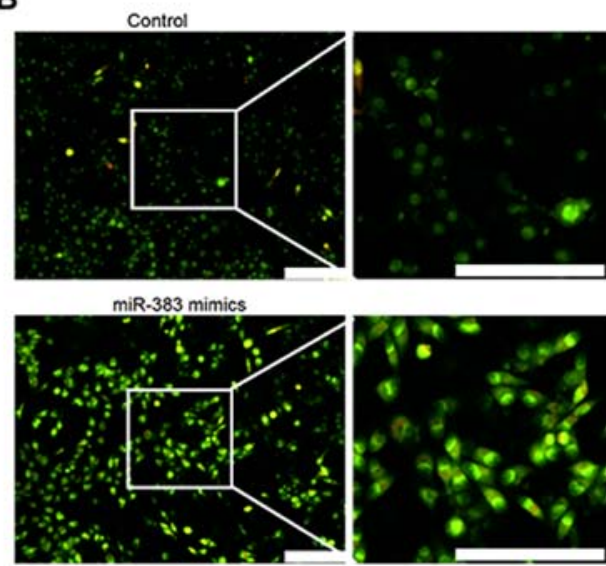

miR-383 inhibito
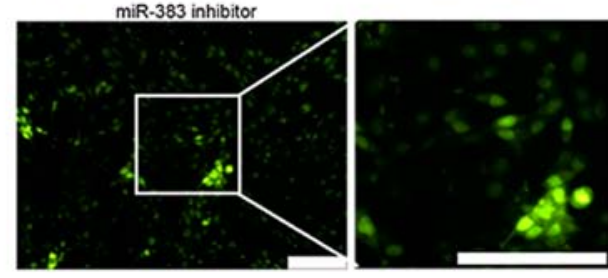

Figure 3. PRDX3 inhibits and miR-383 promotes autophagy in human glioma U87 cells. Autophagy in U87 cells was examined using acridine orange staining in cells transfected with (A) pre-/sh-PRDX3 and (B) miR-383 mimics/inhibitor. Scale bar, $100 \mu \mathrm{m}$. PRDX3, peroxiredoxin 3; miR, microRNA; sh, short hairpin.

cancer cell line (28). PRDX3 is a member of the peroxiredoxin family, which is responsible for neutralizing ROS (29), has been reported to be upregulated in a specific endocrine-regulated tumor (prostate cancer) (24). In androgen-resistant LNCaP cells, PRDX3 protein expression levels have been indicated to be upregulated, thereby preventing $\mathrm{H}_{2} \mathrm{O}_{2}$-induced apoptosis, while PRDX3 knockout has been demonstrated to restore the sensitivity of $\mathrm{H}_{2} \mathrm{O}_{2}$-induced apoptosis. Therefore, PRDX3 may serve an important role in inhibiting apoptosis induced by cell oxidation (24).

Mitochondria have been found to be directly or indirectly associated with the metabolism of cancer cells (30-32), which results in an increased amount of ROS and abnormal mitochondria shape and function (33-35). Oxidative stress is caused by the imbalance between ROS production and the antioxidant capacity of the cells (36). Certain cancer treatments, such as chemotherapy and radiation, have been reported to disrupt mitochondrial homeostasis and induce the release of cytochrome $\mathrm{c}$, resulting in the formation and activation of apoptotic bodies $(37,38)$. This is modulated by the degree of mitochondrial oxidative stress, and previous reports have suggested that mitochondrial oxidative stress may serve an important role in cancer development $(39,40)$.

PRDX3 has been indicated to serve a major role in controlling mitochondrial ROS production (41). In a previous study (41), PRDX3-knockout mice have been reported to be lethargic with aging; moreover, compared with WT mice, PRDX3-knockout mice had increased oxidative damage and a decreased copy number of mitochondrial DNA in skeletal muscle. In addition, the apoptosis of brain cells in PRDX3knockout mice was increased compared with that in WT mice. These results indicated that the lack of PRDX3 accelerated the oxidative stress and mitochondrial damage, resulting in a reduced energy supply and cellular activity (41). Therefore,
PRDX3 may be associated with the inhibition of the aging process (41).

In another study, PRDX3 knockdown in hepatoma cells has been performed to explore whether PRDX3 inhibition may prevent the oxidation of mitochondrial DNA and the downstream ATP synthesis and result in the inhibition of tumor cell growth or apoptosis (42). It was found that PRDX3 mediated mitochondrial oxidative stress to promote tumor growth and migration (42). In the present study, cell apoptosis, ROS levels and autophagy were examined following overexpression and knockdown of PRDX3 (pre-PRDX3 and sh-PRDX3, respectively). The results indicated that sh-PRDX3 increased apoptosis, ROS levels and autophagy in U87 cells, and it was hypothesized that sh-PRDX3 may promote U87 cell apoptosis via ROS-mediated autophagy. These findings are consistent with those of previous studies aforementioned (42).

miRNAs are non-coding RNAs that regulate gene expression and have been associated with cancer pathogenesis $(3,4,7,10)$. Owing to its abnormal downregulation in certain types of human cancers, including gastric cancer and nonsmall cell lung cancer, miR-383 may be employed for cancer treatment and diagnosis by its upregulation $(43,10)$. The gene of miR-383 is localized in the intron of the protein-coding gene $S G C Z$, which is dysregulated in various diseases $(9,10,43)$. A previous study found that miR-383 was downregulated in intestinal gastric adenocarcinoma and it has been suggested that miR-383 may be used as a potential tumor marker for the diagnosis of gastric cancer and as a potential target for gene therapy (43).

The expression level of miR-383 has been reported to be downregulated in U87 human glioma cells and has been negatively associated with the pathological grades of gliomas (44). It has been indicated that decreased miR-383 expression in glioma cells inhibited cell proliferation, migration and invasion, 
A

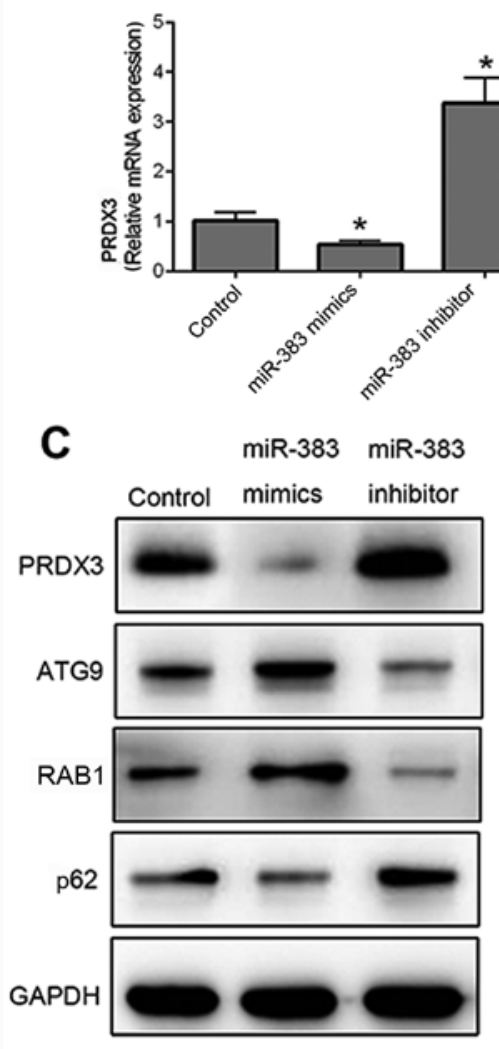

D
B

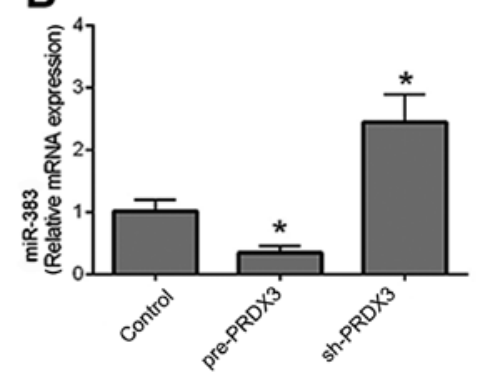

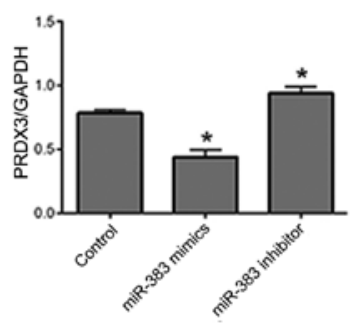
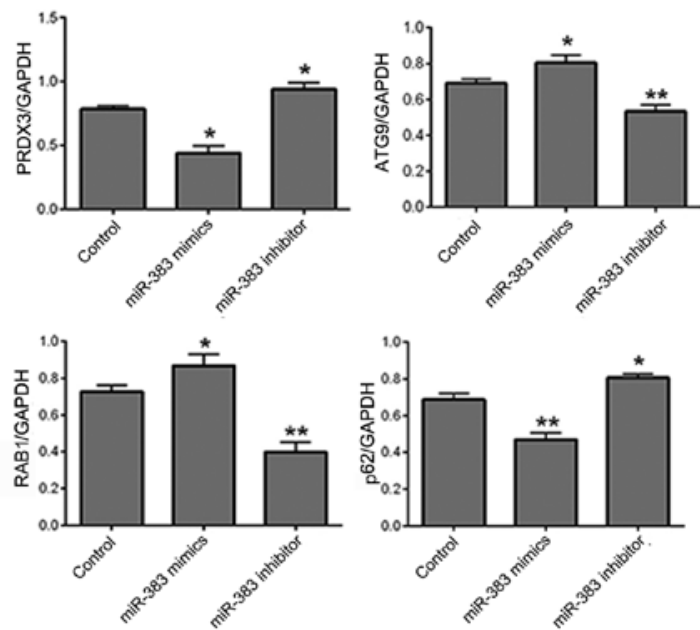

362

369

PRDX3 3' UTR 5'-UUCUGAUCA-3'

hsa-miR-383<smiles>C=CC12C=CC1C=C2</smiles>

3'- AAGACUAGA -5'

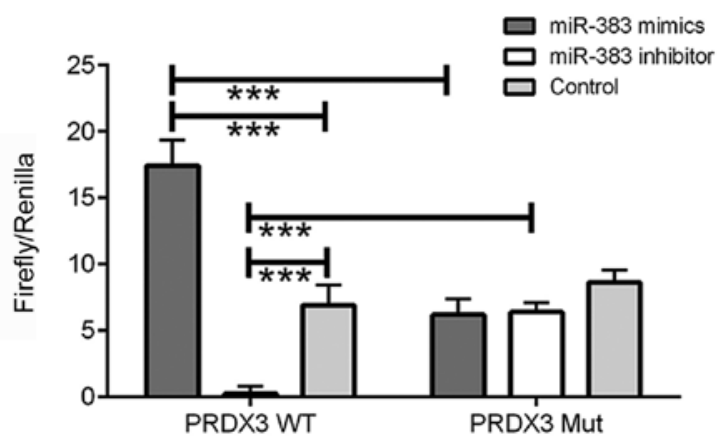

Figure 4. Interaction between miR-383 and PRDX3. Reverse transcription-quantitative PCR was used to detect the mRNA expression of PRDX3 and miR-383 in cells transfected with (A) miR-383 mimics/inhibitor and (B) pre-/sh-PRDX3. (C) The protein expression of PRDX3 and the autophagy-related proteins ATG9, RAB1 and p62 was detected in cells transfected with miR-383 mimics/inhibitor via western blot. (D) The interaction between miR-383 and PRDX3 was evaluated in U87 cells via a dual-luciferase assay. $\mathrm{n}=3$; ${ }^{*} \mathrm{P}<0.05,{ }^{* *} \mathrm{P}<0.01$ and ${ }^{* * *} \mathrm{P}<0.001$ vs. Control group. PRDX3, peroxiredoxin 3; miR, microRNA; sh, short hairpin; ATG9, autophagy-related protein 9; RAB1, Ras-related protein Rab-1; WT, wild-type; Mut, mutant.

affected the cell cycle regulation and induced apoptosis (45). Overexpression of miR-383 was found to inhibit the growth of U251 and U87 glioma cells, downregulate the protein expression level of cyclin D1, and induce cell cycle arrest at the $G_{0} / G_{1}$ phase (44). This is consistent with previous studies in different types of tumors, including colorectal cancer and glioma $(11,46,47)$. In the present study, cell apoptosis, ROS levels and autophagy were examined in cells following transfection with miR-383 mimics and inhibitor. The results indicated that miR-383 mimics increased apoptosis, ROS levels and autophagy in U87 cells, suggesting that miR-383 mimics promoted U87 cell apoptosis via ROS-mediated autophagy. The limitation of this study is that the NC groups were not taken into consideration in the follow-up study after transfection efficiency detection.

Li et al (15) reported that PRDX3 was a target protein of miR-383, and miR-383 has been found to be negatively associated with PRDX3 expression. In the present study, the 
interaction between miR-383 and PRDX3 was also verified. Moreover, as PRDX3 has been indicated to be a key enzyme in oxidative stress and autophagy, it may be hypothesized that miR-383 may serve an antitumor role via regulating the oxidative stress pathway to induce autophagy.

\section{Acknowledgements}

Not applicable.

\section{Funding}

No funding was received.

\section{Availability of data and materials}

The datasets used and/or analyzed during the current study are available from the corresponding author on reasonable request.

\section{Authors' contributions}

$\mathrm{ZX}, \mathrm{XZ}$ and ML performed the experiments. ZX and JL analyzed and interpreted the experimental data. ZX and IC designed the study. ZX was a major contributor to writing the manuscript. IC revised the manuscript. All authors read and approved the final version of the manuscript.

\section{Ethics approval and consent to participate}

Not applicable.

\section{Patient consent for publication}

Not applicable.

\section{Competing interests}

The authors declare that they have no competing interests.

\section{References}

1. Lapointe S, Perry A and Butowski NA: Primary brain tumours in adults. Lancet 392: 432-446, 2018.

2. Piccolo SR and Frey LJ: Clinical and molecular models of glioblastoma multiforme survival. Int J Data Min Bioinform 7: 245-265, 2013.

3. Fasolo F, Di Gregoli K, Maegdefessel L and Johnson JL: Non-coding RNAs in cardiovascular cell biology and atherosclerosis. Cardiovasc Res 115: 1732-1756, 2019.

4. Correia de Sousa M, Gjorgjieva M, Dolicka D, Sobolewski C and Foti M: Deciphering miRNAs' action through miRNA editing. Int J Mol Sci 20: 6249, 2019.

5. Wang F, Liu W, Jin Y, Wang F and Ma J: Prenatal and neonatal exposure to perfluorooctane sulfonic acid results in aberrant changes in miRNA expression profile and levels in developing rat livers. Environ Toxicol 30: 712-723, 2015.

6. Iida A, Shinoe T, Baba Y, Mano H and Watanabe S: Dicer plays essential roles for retinal development by regulation of survival and differentiation. Invest Ophthalmol Vis Sci 52: 3008-3017, 2011.

7. Mohammad SM, Emadodin M and Hamed M: MiR-21: A key player in glioblastoma pathogenesis. J Cell Biochem 119: 1285-1290, 2018.

8. Huang TZ, Wan XC, Alvarez AA, James CD, Song X, Yang Y, Sastry N, Nakano I, Sulman EP, Hu B and Cheng SY: MIR93 (microRNA-93) regulates tumorigenicity and therapy response of glioblastoma by targeting autophagy. Autophagy 15: 1100-1111,2019.
9. Chen L, Guan H, Gu C, Cao Y, Shao J and Wang F: miR-383 inhibits hepatocellular carcinoma cell proliferation via targeting APRIL. Tumour Biol 37: 2497-2507, 2016.

10. Shang Y, Zang A, Li J, Jia Y, Li X, Zhang L, Huo R, Yang J, Feng J, Ge K, et al: MicroRNA-383 is a tumor suppressor and potential prognostic biomarker in human non-small cell lung caner. Biomed Pharmacother 83: 1175-1181, 2016.

11. Zhao LN, Wang P, Liu YH, Cai H, Ma J, Liu LB, Xi Z, Li ZQ, Liu XB and Xue YX: MiR-383 inhibits proliferation, migration and angiogenesis of glioma-exposed endothelial cells in vitro via VEGF-mediated FAK and Src signaling pathways. Cell Signal 30: 142-153, 2017.

12. Jiang MY, Han ZD, Li W, Yue F, Ye J, Li B, Cai Z, Lu JM, Dong W, Jiang X, et al: Mitochondrion-associated protein peroxiredoxin 3 promotes benign prostatic hyperplasia through autophagy suppression and pyroptosis activation. Oncotarget 8: 80295-80302, 2017.

13. Magarin M, Pohl T, Lill A, Schulz H, Blaschke F, Heuser A, Thierfelder L, Donath S and Drenckhahn JD: Embryonic cardiomyocytes can orchestrate various cell protective mechanisms to survive mitochondrial stress. J Mol Cell Cardiol 97: 1-14, 2016.

14. Song IS, Jeong YJ, Seo YJ, Byun JM, Kim YN, Jeong DH, Han J, Kim KT and Jang SW: Peroxiredoxin 3 maintains the survival of endometrial cancer stem cells by regulating oxidative stress. Oncotarget 8: 92788-92800, 2017.

15. Li KK, Pang JC, Lau KM, Zhou L, Mao Y, Wang Y, Poon WS and Ng HK: MiR-383 is downregulated in medulloblastoma and targets peroxiredoxin 3 (PRDX3). Brain Pathol 23: 413-425, 2013.

16. Srivastava RK, Li C, Ahmad A, Abrams O, Gorbatyuk MS, Harrod KS, Wek RC, Afaq F and Athar M: ATF4 regulates arsenic trioxide-mediated NADPH oxidase, ER-mitochondrial crosstalk and apoptosis. Arch Biochem Biophys 609: 39-50, 2016.

17. Chen J, Stimpson SE, Fernandez-Bueno GA and Mathews CE: Mitochondrial reactive oxygen species and type 1 diabetes. Antioxid Redox Signal 29: 1361-1372, 2018.

18. Holzerová E and Prokisch H: Mitochondria: Much ado about nothing? How dangerous is reactive oxygen species production? Int J Biochem Cell Biol 63: 16-20, 2015.

19. Kornfeld OS, Hwang S, Disatnik MH, Chen $\mathrm{CH}$, Qvit N and Mochly-Rosen D: Mitochondrial reactive oxygen species at the heart of the matter: New therapeutic approaches for cardiovascular diseases. Circ Res 116: 1783-1799, 2015.

20. Liu KM, Chuang SM, Long CY, Lee YL, Wang CC, Lu MC, Lin RJ, Lu JH, Jang MY, Wu WJ, et al: Ketamine-induced ulcerative cystitis and bladder apoptosis involve oxidative stress mediated by mitochondria and the endoplasmic reticulum. Am J Physiol Renal Physiol 309: F318-F331, 2015.

21. Christen V, Camenzind $M$ and Fent K: Silica nanoparticles induce endoplasmic reticulum stress response, oxidative stress and activate the mitogen-activated protein kinase (MAPK) signaling pathway. Toxicol Rep 1: 1143-1151, 2014.

22. Cominacini L, Mozzini C, Garbin U, Pasini A, Stranieri C, Solani E, Vallerio P, Tinelli IA and Fratta Pasini A: Endoplasmic reticulum stress and $\mathrm{Nrf} 2$ signaling in cardiovascular diseases. Free Radic Biol Med 88: 233-242, 2015.

23. Filomeni G, De Zio D and Cecconi F: Oxidative stress and autophagy: The clash between damage and metabolic needs. Cell Death Differ 22: 377-388, 2015.

24. Muriach M, Flores-Bellver M, Romero FJ and Barcia JM: Diabetes and the brain: Oxidative stress, inflammation, and autophagy. Oxid Med Cell Longev 2014: 102158, 2014.

25. Livak KJ and Schmittgen TD: Analysis of relative gene expression data using real-time quantitative PCR and the 2(-Delta Delta C(T)) method. Methods 25: 402-408, 2001.

26. Basu A, Banerjee H, Rojas H, Martinez SR, Roy S, Jia Z, Lilly MB, De León M and Casiano CA: Differential expression of peroxiredoxins in prostate cancer: Consistent upregulation of PRDX3 and PRDX4. Prostate 71: 755-765, 2011.

27. Moreira EF, Kantorow $M$ and Rodriguez IR: Peroxiredoxin 3 (PDRX3) is highly expressed in the primate retina especially in blue cones. Exp Eye Res 86: 452-455, 2008.

28. Whitaker HC, Patel D, Howat WJ, Warren AY, Kay JD, Sangan T, Marioni JC, Mitchell J, Aldridge S, Luxton HJ, et al: Peroxiredoxin-3 is overexpressed in prostate cancer and promotes cancer cell survival by protecting cells from oxidative stress. $\mathrm{Br}$ J Cancer 109: 983, 2013.

29. Lee YJ: Knockout mouse models for peroxiredoxins. Antioxidants (Basel) 9: 182, 2020. 
30. Lamb R, Ozsvari B, Lisanti CL, Tanowitz HB, Howell A, Martinez-Outschoorn UE, Sotgia F and Lisanti MP: Antibiotics that target mitochondria effectively eradicate cancer stem cells, across multiple tumor types: Treating cancer like an infectious disease. Oncotarget 6: 4569-4584, 2015.

31. Li JZ, Ke Y, Misra HP, Trush MA, Li YR, Zhu H and Jia Z: Mechanistic studies of cancer cell mitochondria- and NQO1mediated redox activation of beta-lapachone, a potentially novel anticancer agent. Toxicol Appl Pharmacol 281: 285-293, 2014.

32. Vayalil PK, Oh JY, Zhou F, Diers AR, Smith MR, Golzarian H, Oliver PG, Smith RA, Murphy MP, Velu SE and Landar A: A novel class of mitochondria-targeted soft electrophiles modifies mitochondrial proteins and inhibits mitochondrial metabolism in breast cancer cells through redox mechanisms. PLoS One 10: e0120460, 2015.

33. Hrycay EG and Bandiera SM: Involvement of cytochrome $\mathrm{P} 450$ in reactive oxygen species formation and cancer. Adv Pharmacol 74: 35-84, 2015.

34. Doktorova H, Hrabeta J, Khalil MA and Eckschlager T: Hypoxiainduced chemoresistance in cancer cells: The role of not only HIF-1. Biomed Pap Med Fac Univ Palacky Olomouc Czech Repub 159: 166-177, 2015.

35. SzarekE, BallER, Imperiale A, Tsokos M,Faucz FR, Giubellino A, Moussallieh FM, Namer IJ, Abu-Asab MS, Pacak K, et al: Carney triad, SDH-deficient tumors, and $\mathrm{Sdhb}^{+/-}$mice share abnormal mitochondria. Endocr Relat Cancer 22: 345-352, 2015.

36. Moloney JN and Cotter TG: ROS signalling in the biology of cancer. Semin Cell Dev Biol 80: 50-64, 2018.

37. Pörn-Ares MI, Ares MP and Orrenius S: Calcium signalling and the regulation of apoptosis. Toxicol In Vitro 12: 539-543, 1998

38. Wu CH, Li J, Li L, Sun J, Fabbri M, Wayne AS, Seeger RC and Jong AY: Extracellular vesicles derived from natural killer cells use multiple cytotoxic proteins and killing mechanisms to target cancer cells. J Extracell Vesicles 8: 1588538, 2019.

39. Song IS, Kim HK, Jeong SH, Lee SR, Kim N, Rhee BD, Ko KS and Han J: Mitochondrial peroxiredoxin III is a potential target for cancer therapy. Int J Mol Sci 12: 7163-7185, 2011.
40. Kudryavtseva AV, Krasnov GS, Dmitriev AA, Alekseev BY, Kardymon OL, Sadritdinova AF, Fedorova MS, Pokrovsky AV, Melnikova NV, Kaprin AD, et al: Mitochondrial dysfunction and oxidative stress in aging and cancer. Oncotarget 7: 44879-44905, 2016.

41. Zhang YG, Wang L, Kaifu T, Li J, Li X and Li L: Accelerated decline of physical strength in peroxiredoxin-3 knockout mice. Exp Biol Med (Maywood) 241: 1395, 2016.

42. Liu Z, Hu Y, Liang H, Sun Z, Feng S and Deng H: Silencing PRDX3 inhibits growth and promotes invasion and extracellular matrix degradation in hepatocellular carcinoma cells. J Proteome Res 15: 1506-1514, 2016.

43. Azarbarzin S, Feizi MAH, Safaralizadeh R, Kazemzadeh M and Fateh A: The value of miR-383, an intronic miRNA, as a diagnostic and prognostic biomarker in intestinal-type gastric cancer. Biochem Genet 55: 244-252, 2017.

44. Xu Z, Zeng X, Tian D, Xu H, Cai Q, Wang J and Chen Q MicroRNA-383 inhibits anchorage-independent growth and induces cell cycle arrest of glioma cells by targeting CCND1. Biochem Biophys Res Commun 453: 833-838, 2014.

45. Xu D, Ma P, Gao G, Gui Y, Niu X and Jin B: MicroRNA-383 expression regulates proliferation, migration, invasion, and apoptosis in human glioma cells. Tumor Biol 36: 7743-7753, 2015.

46. Yin M, Wang X, Yao G, Lü M, Liang M, Sun Y and Sun F: Transactivation of micrornA-320 by microRNA-383 regulates granulosa cell functions by targeting $\mathrm{E} 2 \mathrm{~F} 1$ and $\mathrm{SF}-1$ proteins. J Biol Chem 289: 18239-18257, 2014.

47. Fateh A, Hosseinpour Feizi MA, Safaralizadeh R, Somi MH, Ravanbakhsh R, Shokoohi B, Hashemzadeh S and Azarbarzin S: Prognostic and predictive roles of microRNA-383 in colorectal cancer. Gastroenterol Insights 7: 1-14, 2016.

This work is licensed under a Creative Commons Attribution-NonCommercial-NoDerivatives 4.0 International (CC BY-NC-ND 4.0) License. 